\title{
THE EFFECT OF BILATERAL STELLATE GANGLION BLOCK ON THE CEREBRAL CIRCULATION IN NORMOTENSIVE AND HYPERTENSIVE PATIENTS ${ }^{1}$
}

\author{
By M. H. HARMEL, ${ }^{2,3}$ J. H. HAFKENSCHIEL, G. M. AUSTIN,
} C. W. CRUMPTON, ${ }^{4}$ and S. S. KETY

\author{
(From the Departments of Pharmacology and Anesthesiology, the Edward B. Robinctte \\ Foundation, Medical Clinic, Hospital of the University of Pennsylvania, and \\ the Harrison Department of Surgical Research, University of \\ Pennsylvania School of Medicine)
}

(Received for publication December 12, 1948)

Stellate ganglion block has been used in the treatment of cerebral derangements thought to be associated with angiospasm, for the purpose of relieving spasm and presumably increasing the cerebral blood flow (1-4). In view of this clinical development the question of the role of the sympathetic nervous system in the control of the cerebral circulation becomes more than an academic one. The only experimental work in man has been that of Risteen and Volpitto (3) who observed through burr holes an increase in the diameter of the pial vessels following stellate block. A number of clinical observations, ascribing dramatic results of stellate block to the release of cerebral angiospasm, have appeared since Leriche and Fontaine (1) first reported their experience with two cases of cerebral embolism. With the development of the nitrous oxide method for measuring cerebral blood flow (5-7) a quantitative technique has been made available for clinical study of this problem. Quantitative data can be obtained concerning the fundamental physiology of the cerebral circulation following block of that part of the sympathetic innervation of the cerebral vessels passing through the stellate and middle cervical ganglia. This information may permit evaluation of stellate block as a means of

1 This work was supported in part by grants to the Department of Pharmacology of the University of Pennsylvania from the Committee on Research in Dementia Precox, founded by the Supreme Council $33^{\circ}$ Scottish Rite, Northern Masonic Jurisdiction, U. S. A., and from the Life Insurance Medical Research Fund.

2 National Research Council Fellow in Anesthesiology, 1946-1947.

3 Present address: Department of Anesthesia, Albany Hospital, Albany 1, N. Y.

${ }^{4}$ Fellow of the National Institute of Health, 1948-1949. therapy in cerebro-vascular derangements. The following studies were undertaken in an effort to explore these problems.

\section{METHODS}

Thirteen patients were studied; their diagnoses are given in Table I. In all patients except A.S. and J. C. there was a therapeutic or diagnostic indication for performing stellate block. With the exception of $\mathrm{R}$. H., all patients were ambulatory and in full possession of their faculties. R. H. had been injured three weeks prior to the study and was aphasic and disoriented at the time of study. The patients with Parkinsonism were studied as outpatients. All the hypertensive patients came from the medical wards.

Mean arterial blood pressure (MABP) was measured from the femoral artery by a damped mercury manometer attached directly to a needle in the artery. Blood oxygen and carbon dioxide analyses were carried out by the manometric technique of Van Slyke and Neill (8). Blood $\mathrm{pH}$ measurements were made anaerobically at $37^{\circ} \mathrm{C}$. using a glass electrode. Carbon dioxide tensions $\left(\mathrm{pCO}_{2}\right)$ were calculated according to the nomograms in Peters and Van Slyke (8). Cerebral blood flow (CBF) was determined by the nitrous oxide method using $21 \%$ oxygen, $64 \%$ nitrogen and $15 \%$ nitrous oxide as the inspired gas mixture $(6,7)$. From this value and the mean arterial blood pressure the cerebral vascular resistance was calculated (6).

The patients received no medication prior to the study. Following a control cerebral blood flow measurement bilateral block of the stellate ganglia was performed using the technique described by Pereira (9). Either $1 \%$ procaine or $1 \%$ intracaine without adrenalin was used, $20 \mathrm{cc}$. of solution being injected on either side. The criteria for an effective block were: scleral and conjunctival injection, ptosis, narrowing of the palpebral fissure, miosis and anhydrosis of the forehead. The block was usually evident within five minutes, reached its height within 15 minutes and lasted from 45 to 60 minutes. When block of the second side was judged to be complete, a second cerebral blood flow measurement was performed. 
TABLE I

Effect of bilateral stellate ganglion block on blood constituents

\begin{tabular}{|c|c|c|c|c|c|c|c|c|c|c|c|c|c|c|c|c|c|c|}
\hline \multirow{3}{*}{ Patient } & \multirow{3}{*}{ Age } & \multirow{3}{*}{ Diagnosis } & \multicolumn{4}{|c|}{ Blood $\mathrm{CO}_{2}$ content } & \multicolumn{4}{|c|}{ Blood $\mathrm{CO}_{2}$ tension } & \multicolumn{4}{|c|}{ Blood $\mathrm{O}_{2}$ content } & \multicolumn{4}{|c|}{ Blood pH } \\
\hline & & & \multicolumn{2}{|c|}{ Arterial } & \multicolumn{2}{|c|}{ Int. jugular } & \multicolumn{2}{|c|}{ Arterial } & \multicolumn{2}{|c|}{ Int. jugular } & \multicolumn{2}{|c|}{ Arterial } & \multicolumn{2}{|c|}{ Int. jugular } & \multicolumn{2}{|c|}{ Arterial } & \multicolumn{2}{|c|}{ Int. jugular } \\
\hline & & & $\mathrm{C}^{*}$ & $\mathrm{E} \dagger$ & $\mathrm{C}$ & $\mathrm{E}$ & $\mathrm{C}$ & $\mathrm{E}$ & C & $\mathrm{E}$ & C & $\mathrm{E}$ & $\mathrm{C}$ & $\mathrm{E}$ & $\mathrm{C}$ & $\mathrm{E}$ & $\mathrm{C}$ & $\mathrm{E}$ \\
\hline & & & $\begin{array}{c}\text { Vol. } \\
\%\end{array}$ & $\begin{array}{c}\text { Vol. } \\
\%\end{array}$ & $\begin{array}{l}\text { Vol. } \\
\%\end{array}$ & $\begin{array}{l}\text { Vol. } \\
\%\end{array}$ & $\underset{H g}{m m}$. & $\underset{\mathrm{Hg}}{m m}$. & $\underset{\mathrm{Hg}}{\mathrm{mm}}$ & $\underset{H g}{m m}$ & $\begin{array}{c}\text { Vol. } \\
\%\end{array}$ & $\begin{array}{l}\text { Vol. } \\
\%\end{array}$ & $\begin{array}{c}\text { Vol. } \\
\%\end{array}$ & $\begin{array}{l}\text { Vol. } \\
\%\end{array}$ & & & & \\
\hline J. C. & 74 & $\begin{array}{l}\text { Normotensive } \\
\text { with } \\
\text { Cirrhosis }\end{array}$ & 47.4 & 47.5 & 52.0 & 52.9 & 35 & 34 & 37 & 38 & 16.4 & 15.9 & 10.4 & 10.3 & 7.45 & 7.45 & 7.44 & 7.42 \\
\hline A. S. & 42 & $\begin{array}{l}\text { Normotensive } \\
\text { with Syphilis }\end{array}$ & 49.7 & 45.8 & 54.2 & 54.0 & 42 & 34 & 47 & 40 & 15.7 & 15.9 & 10.0 & 8.0 & 7.39 & 7.47 & 7.34 & 7.42 \\
\hline B. C. & 25 & $\begin{array}{l}\text { Normotensive } \\
\text { with } \\
\text { Headache }\end{array}$ & 51.3 & 50.5 & 56.2 & 55.6 & & & & & 17.8 & 17.6 & 12.4 & 11.8 & & & & \\
\hline B. P. & 44 & Hypertensive & 45.1 & 46.5 & 53.2 & 53.5 & 38 & 38 & 45 & 46 & 19.3 & 19.5 & 11.0 & 12.0 & 7.42 & 7.42 & 7.37 & 7.38 \\
\hline E. L. & 43 & Hypertensive & 50.3 & 48.9 & 54.8 & 55.3 & 39 & 36 & 44 & 42 & 16.5 & 16.5 & 10.4 & 9.9 & 7.44 & 7.46 & 7.40 & 7.41 \\
\hline M. O. & 48 & Hypertensive & 51.0 & 46.9 & 58.1 & 54.7 & 37 & 33 & 42 & 38 & 18.0 & 18.0 & 10.6 & 11.1 & 7.48 & 7.49 & 7.44 & 7.47 \\
\hline N.S. & 47 & $\begin{array}{l}\text { Hypertensive } \\
\text { with C.V.A.t }\end{array}$ & 51.4 & 49.8 & 58.6 & 57.0 & 37 & 39 & 42 & 41 & 17.8 & 18.2 & 9.7 & 10.4 & 7.50 & 7.44 & 7.44 & 7.38 \\
\hline M. G. & 44 & $\begin{array}{c}\text { Hypertensive } \\
\text { Hemiplegia }\end{array}$ & 57.1 & 57.4 & 61.0 & 62.0 & 36 & 40 & 45 & 44 & 12.4 & 12.3 & 7.4 & 7.2 & 7.51 & 7.48 & 7.44 & 7.45 \\
\hline F.P. & 33 & Hemiplegia & 49.3 & 49.8 & 56.0 & 56.8 & & & & & 16.7 & 16.7 & 8.7 & 8.2 & & & & \\
\hline D. 'T. & 28 & $\begin{array}{l}\text { Parkinson's } \\
\text { Disease }\end{array}$ & 50.3 & 47.9 & 55.4 & 54.7 & 39 & 40 & 45 & 46 & 16.9 & 17.2 & 10.3 & 11.2 & 7.43 & 7.40 & 7.38 & 7.36 \\
\hline A. P. & 40 & $\begin{array}{l}\text { Parkinson's } \\
\text { Disease }\end{array}$ & 48.4 & 49.4 & 54.4 & 54.9 & 34 & 36 & 49 & 49 & 15.7 & 15.7 & 9.4 & 10.1 & 7.40 & 7.38 & 7.34 & 7.34 \\
\hline L. C. & 35 & $\begin{array}{l}\text { Parkinson's } \\
\text { Disease }\end{array}$ & 44.6 & 40.0 & 49.7 & 48.4 & 41 & 32 & 43 & 41 & 17.5 & 18.0 & 11.2 & 9.7 & 7.40 & 7.44 & 7.36 & 7.38 \\
\hline R. H. & 23 & Head Injury & 51.5 & 51.8 & 55.8 & 56.0 & & & & & 20.2 & 20.3 & 15.0 & 15.0 & & & & \\
\hline Mean & 44 & & 49.5 & 48.6 & 55.3 & 54.8 & 38 & 36 & 44 & 43 & 17.0 & 17.1 & 10.1 & 10.0 & 7.44 & 7.45 & 7.40 & 7.40 \\
\hline
\end{tabular}

TABLE II

Effect of bilateral stellate ganglion block on cerebral circulation and metabolism

\begin{tabular}{|c|c|c|c|c|c|c|c|c|c|c|c|c|}
\hline \multirow{2}{*}{ Patient } & \multicolumn{2}{|c|}{$\begin{array}{l}\text { (CBF) Cerebral } \\
\text { blood flow }\end{array}$} & \multicolumn{2}{|c|}{$\begin{array}{l}\left(\mathrm{CMRO}_{2}\right) \text { Cerebral } \\
\text { metabolic rate }\end{array}$} & \multicolumn{2}{|c|}{$\begin{array}{l}\text { (CVR) Cerebral vascular } \\
\text { resistance }\end{array}$} & \multicolumn{2}{|c|}{$\begin{array}{l}\text { (MABP) Mean } \\
\text { arterial B.P. }\end{array}$} & \multicolumn{2}{|c|}{$\mathrm{A}-\mathrm{VO}_{2} \ddagger$} & \multicolumn{2}{|c|}{$\mathrm{KQ} \S$} \\
\hline & $\mathrm{C}^{*}$ & $\mathrm{E}+$ & C & $\mathrm{E}$ & $\mathrm{C}$ & $\mathrm{E}$ & $\mathrm{C}$ & $\mathrm{E}$ & $\mathrm{C}$ & $\mathrm{E}$ & C & $\mathrm{E}$ \\
\hline & $\begin{array}{l}\text { cc. } / 100 \mathrm{~g} .1 \\
\min .\end{array}$ & $\begin{array}{c}c c . / 100 \mathrm{~g} . / \\
\text { min. }\end{array}$ & $\underset{\text { min. }}{\text { cc. } / 100 \mathrm{~g} . /}$ & $\begin{array}{c}\text { cc. } / 100 \mathrm{~g} . / \\
\mathrm{min} .\end{array}$ & $\frac{m m . H g}{\substack{c c .100 g . / \\
\text { min. }}}$ & $\frac{m m . H g}{c c / 100 \mathrm{~g} . /}$ & & & $\begin{array}{l}\text { Vol. } \\
\%\end{array}$ & $\begin{array}{c}\text { Vol. } \\
\%\end{array}$ & & \\
\hline J. C. & 44 & 46 & 2.6 & 2.6 & 2.1 & 2.2 & 93 & 100 & 6.0 & 5.6 & 0.77 & 0.96 \\
\hline A. S. & 42 & 38 & 2.4 & 3.0 & 2.0 & 2.0 & 85 & 77 & 5.7 & 7.8 & 0.79 & 1.05 \\
\hline B. C. & 69 & 66 & 3.7 & 3.8 & 1.5 & 1.6 & 101 & 105 & 5.4 & 5.8 & 0.91 & 0.88 \\
\hline B. $\mathrm{P}$. & 43 & 52 & 3.6 & 3.9 & 3.1 & 3.1 & 134 & 159 & 8.3 & 7.5 & 0.98 & 0.93 \\
\hline E. L. & 45 & 36 & 2.7 & 2.4 & 4.1 & 5.3 & 182 & 189 & 6.1 & 6.6 & 0.74 & 0.97 \\
\hline M. O. & 59 & 42 & 4.4 & 2.8 & 3.2 & 3.9 & 186 & 163 & 7.4 & 6.9 & 0.96 & 1.13 \\
\hline N.S. & 46 & 42 & 3.7 & 3.3 & 3.0 & 3.4 & 140 & 142 & 8.1 & 7.8 & 0.88 & 0.92 \\
\hline M. G. & 59 & 54 & 3.0 & 2.8 & 2.9 & 3.2 & 170 & 173 & 5.0 & 5.1 & 0.80 & 0.90 \\
\hline F.P. & 33 & 32 & 2.6 & 2.7 & 2.8 & 2.8 & 91 & 90 & 8.0 & 8.5 & 0.84 & 0.71 \\
\hline D. T. & 47 & 54 & 3.1 & 3.2 & 2.2 & 2.0 & 105 & 109 & 6.6 & 6.0 & 0.78 & 0.97 \\
\hline A. P. & 53 & 65 & 3.3 & 3.3 & 1.7 & 1.5 & 98 & 115 & 6.4 & 5.6 & 0.95 & 0.97 \\
\hline L. C. & 60 & 52 & 3.8 & 4.3 & 1.6 & 1.8 & 92 & 97 & 6.3 & 8.3 & 0.81 & 1.01 \\
\hline R. H. & 39 & 42 & 2.8 & 2.2 & 2.9 & 2.8 & 97 & 96 & 7.2 & 5.2 & 0.88 & 0.81 \\
\hline Mean & \multirow{2}{*}{\multicolumn{2}{|c|}{54}} & 3.2 & 3.1 & 2.5 & 2.7 & 121 & 124 & 6.7 & 6.7 & 0.85 & 0.94 \\
\hline Normal & & & \multicolumn{2}{|c|}{$\begin{array}{ll}3.2 & 3.3\end{array}$} & \multicolumn{2}{|c|}{1.6} & \multicolumn{2}{|c|}{86} & \multicolumn{2}{|c|}{6.3} & \multicolumn{2}{|c|}{0.99} \\
\hline
\end{tabular}

$* \mathrm{C}=$ Control. $\quad \dagger \mathrm{E}=$ Post bilateral stellate block. $\quad \ddagger \mathrm{A}-\mathrm{VO}_{2}=$ Cerebral arterio-venous oxygen difference. $\$ \mathrm{RQ}=$ Cerebral respiratory quotient. 
RESULTS

The data are presented in Tables I and II. It will be seen that the patients comprise a clinically heterogeneous group. In the series as a whole neither the cerebral blood flow nor the cerebral vascular resistance was significantly changed following the stellate ganglion block. However, when the hypertensive group is considered separately, there is a significant increase in cerebral vascular resistance $(3.3$ to $3.8, \mathrm{p}<0.05)$ with no significant change in the other functions studied. The predominance of hypertensive persons explains the high mean arterial blood pressures recorded. The cerebral vascular resistance is considerably elevated for the hypertensive patients in this group as previously described (10). We feel that the cerebral vascular resistance most explicitly conveys information concerning the tonic state of the cerebral vessels. It seems unlikely that changes in intracranial pressure or blood viscosity of a magnitude sufficient to affect cerebral vascular resistance occurred during these experiments (11).

\section{DISCUSSION}

Our observation that bilateral stellate ganglion block in our patients produced no measurable change in the cerebral circulation is in contrast with the presumption that this procedure leads to dilatation of the cerebral vessels and an increase in cerebral blood flow (1-4). It does not, however, prove that the cerebral blood vessels of man are without sympathetic control, nor rule out the possibility that under abnormal conditions there may be vasospasm of sympathetic origin. To prove the former, one must be certain of having excluded all sympathetic nerve impulses to the brain. This cannot be assured even for those impulses which pass through the stellate ganglia, for the local block may have been incomplete. Complete surgical extirpation of the stellate ganglia would undoubtedly be the best approach in studying the physiology of the intrinsic nervous control of the cerebral circulation (12). Local block, though admittedly less certain of interrupting the sympathetic pathways, is the technique used currently in clinical therapy. Furthermore it is by no means certain that all the sympathetic fibers to the brain pass through the stellate gan- glia $(13,14)$. As for the possibility that the situation may be different under other clinical conditions, such as acute angiospasm, only further study can give an adequate answer. None of the subjects of these experiments showed any symptoms suggesting acute cerebral angiospasm.

An apparent increase in the cerebral vascular resistance of the hypertensive patients calls for comment. We feel that this was probably the result of a relatively greater flow through the facial veins causing a greater extracerebral contamination in the presence of an unchanged cerebral blood flow. On the basis of this hypothesis one would expect an increased cerebral vascular resistance, a decreased cerebral blood flow (50 to 45) and a decreased cerebral oxygen uptake (3.5 to 3.0). Although these latter changes are not statistically significant they are in a direction compatible with the thesis. That this should occur in the hypertensive group and not in the other patients may be explained by the higher mean perfusing pressure during the block in these patients. These findings indicate that the usually small error in the nitrous oxide method due to contamination (6) may be magnified when blood flow through the skin is significantly increased.

We conclude that quantitative measurements of the cerebral blood flow in man gives no indication that bilateral stellate block causes an increase in cerebral blood flow or diminution in the tone of cerebral vessels. These results are compatible with the thesis that the sympathetic nervous system plays little role in the intrinsic control of the cerebral circulation under the conditions studied (including essential hypertension). An evaluation of the mechanism of improvement following stellate block as a therapeutic measure in man cannot be made until studies have been made in patients presumed to have acute cerebral angiospasm.

\section{SUMMARY}

1. In 13 patients quantitative studies of the cerebral blood flow and cerebral vascular resistance were made using the nitrous oxide technique before and after bilateral block of the stellate ganglia.

2. There were no significant changes in any of the functions studied before and after block. 


\section{BIBLIOGRAPHY}

1. Leriche, R., and Fontaine, R., Infiltration of the stellate in cerebral embolism. Rev. de Chir., 1936, 74, 755 .

2. Mackey, W. A., and Scott, L. D. W., The treatment of apoplexy by infiltration of stellate ganglion with novocain. Brit. M. J., 1938, 2, 1.

3. Risteen, W. A., and Volpitto, P. P., Role of stellate ganglion block in certain neurologic disorders. South. M. J., 1946, 39, 431.

4. Gilbert, N. C., and de Takats, Geza, Emergency treatment of apoplexy. J. A. M. A., 1948, 136, 659.

5. Kety, S. S., and Schmidt, C. F., The determination of cerebral blood flow in man by the use of nitrous oxide in low concentrations. Am. J. Physiol., 1945, 143, 53.

6. Kety, S. S., and Schmidt, C. F., The nitrous oxide method for quantitative determination of cerebral blood flow in man: theory, procedure and normal values. J. Clin. Invest., 1948, 27, 476.

7. Kety, S. S., The quantitative determination of cerebral blood flow in man. Methods in Medical Research, Year Book Publishers, Chicago, 1948, Vol. I.

8. Peters, John P., and Van Slyke, Donald D., Quanti- tative Clinical Chemistry. Williams and Wilkins, Baltimore, 1931.

9. Pereira, A., de Sousa, Blocking of the middle cervical and stellate ganglions with descending infiltration anesthesia: technic, accidents and therapeutic indications. Arch. Surg., 1945, 50, 152.

10. Kety, S. S., Hafkenschiel, J. H., Jeffers, W. A., Leopold, I. H., and Shenkin, H. A., The blood flow, vascular resistance and oxygen consumption of the brain in essential hypertension. J. Clin. Invest., 1948, 27, 511.

11. Kety, S. S., Shenkin, H. A., and Schmidt, C. F., The effects of increased intracranial pressure on cerebral circulatory functions in man. J. Clin. Invest., 1948, 27, 493.

12. Shenkin, Henry A., Studies on the cerebral circulation in man following bilateral stellate ganglionectomy. Unpublished observations.

13. Chorobski, J., and Penfield, W., Cerebral vasodilator nerves and their pathways from the medulla oblongata. Arch. Neurol. and Psychiat., 1932, 28, 1257.

14. McNaughton, F. L., Innervation of the intracranial blood vessels and dural sinuses. A. Research Nerv. \& Ment. Dis., Proc., 1938, 18, 178. 